\title{
Novel Fluorophores for Single-Molecule Imaging
}

\author{
Katherine A. Willets, Oksana Ostroverkhova, Meng He, ${ }^{\dagger, \neq}$ Robert J. Twieg, ${ }^{\dagger}$ and W. E. Moerner* \\ Department of Chemistry, Stanford University, Stanford, California 94305
}

Received October 25, 2002 ; E-mail:wmoerner@stanford.edu

The development of new fluorescent dyes for single-molecule imaging is an important challenge due to the numerous problems in biomolecular and materials science that may benefit from insight at the level of individual molecules. ${ }^{1-5}$ Fluorophores for singlemolecule studies must show strong absorption, very high fluorescence quantum yield, weak bottlenecks into triplet states, and high photostability. At room temperature, these requirements have previously been fulfilled by biological fluorescent labels based on laser dyes (such as rhodamines, cyanines, oxazines, etc. ${ }^{6,7}$ or by derivatives of rigid polynuclear aromatic hydrocarbons such as terrylene ${ }^{8,9}$ or perylene. ${ }^{10-12}$

We have discovered a new class of fluorophores that can be imaged at the single-molecule level and offer additional beneficial properties such as a significant ground-state dipole moment $\mu_{\mathrm{g}}$, moderate hyperpolarizability, and viscosity-dependent fluorescence. These molecules contain an amine donor and a dicyanodihydrofuran (DCDHF) acceptor linked by a conjugated unit (benzene, thiophene, alkene, styrene, etc.) and were originally designed to deliver both high polarizability anisotropy and $\mu_{\mathrm{g}}$ as nonlinear optical chromophores for photorefractive polymer/glass applications. ${ }^{13,14}$ Surprisingly, these molecules are also well-suited for single-molecule fluorescence applications. Here we report the bulk (ensemble) and single-molecule photophysical properties for several examples in this new class of single-molecule reporters.

The structures of the dyes studied are shown in Figure 1; all have been easily observed at the single-copy level (vide infra). The measured properties are reported in Table 1. Absorption and emission spectra were measured in toluene (J.T. Baker, spectroscopic grade) using a Perkin-Elmer Lambda 19 UV-vis spectrometer and a Fluoromax 2 fluorimeter, respectively, and their respective maxima are reported as $\lambda_{\mathrm{abs}}{ }^{\max }$ and $\lambda_{\mathrm{em}}{ }^{\mathrm{max}}$. From the absorption spectra, the maximum value of the molar extinction coefficient $\left(\epsilon_{\max }\right)$ was calculated for each dye using Beer's Law. The fluorescence quantum yield $\left(\Phi_{\mathrm{F}}\right)$ of each dye in toluene was determined by comparison with a (comparably absorbing) reference dye in solution with a known $\Phi_{\mathrm{F} .}{ }^{7,15}$ The $\Phi_{\mathrm{F}}$ values for $\mathbf{1 - 4}$ in solution are moderate, on a par with the well-known single-molecule label Cy5, ${ }^{15}$ but well below the $90 \%$ values for rhodamines. ${ }^{16}$ However, the fluorescence quantum yields found for $\mathbf{5}$ and $\mathbf{6}$ in solution seem surprisingly low given that single molecules of each of these dyes could also be imaged in films of poly(methyl methacrylate) (PMMA) (vide infra).

To resolve this issue, we measured the $\Phi_{\mathrm{F}}$ values of dye-doped polymer films spun from solutions of dye in PMMA/toluene $(20 \%$ $\mathrm{m} / \mathrm{m}$ ); the values were significantly improved in the polymer matrix (Table 1). ${ }^{17}$ Because $\Phi_{\mathrm{F}}$ measurements in bulk films can present well-known issues with dimer formation and self-absorption, the $\Phi_{\mathrm{F}}$ values were measured at the lowest possible dye concentrations. Nevertheless, the film $\Phi_{\mathrm{F}}$ values were still dependent on concentration for several of the dyes; for example, the $\Phi_{\mathrm{F}}$ of $\mathbf{5}$ improved

\footnotetext{
$\dagger$ Department of Chemistry, Kent State University, Kent, OH 44242.

¥ Present address: PPG Industries, Pittsburgh, PA.
}
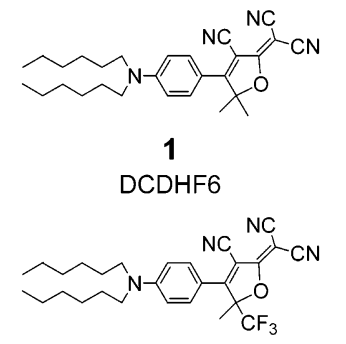

3

DCDHF6-CF3

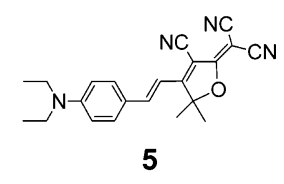

DCDHF-2V
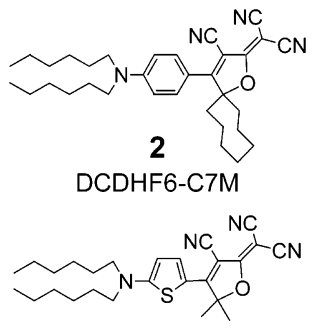

4

TH-DCDHF6

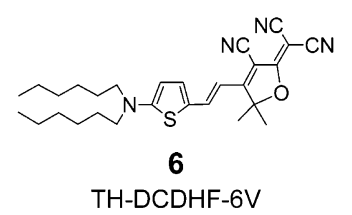

TH-DCDHF-6V

Figure 1. Structures and informal names of the fluorophores.

Table 1. Photophysical Parameters for a New Class of Single-Molecule Fluorophores

\begin{tabular}{lccrcccc}
\hline & $\begin{array}{c}\lambda_{\text {abs }}{ }^{\max } \\
(\mathrm{nm})\end{array}$ & $\begin{array}{c}\lambda_{\mathrm{em}}{ }^{\max } \\
(\mathrm{nm})\end{array}$ & $\begin{array}{c}\epsilon_{\max } \\
\left(\mathrm{M}^{-1} \mathrm{~cm}^{-1}\right)\end{array}$ & \multicolumn{1}{c}{$\Phi_{\mathrm{F}}{ }^{a}$} & $\begin{array}{c}\Phi_{\mathrm{B}}{ }^{b} \\
\left(10^{-7}\right)\end{array}$ & $\begin{array}{c}N_{\text {total }}{ }^{\mathrm{c}} \\
\left(10^{4}\right)\end{array}$ & $\begin{array}{c}\mu_{\mathrm{g}} \\
\left(10^{-30} \mathrm{C} \mathrm{m}\right)\end{array}$ \\
\hline $\mathbf{1}$ & 486 & 505 & 71,000 & $0.10(0.92)$ & 8.9 & 25 & 38 \\
$\mathbf{2}$ & 486 & 505 & 76,000 & $0.10(0.95)$ & 7.5 & 23 & 36 \\
$\mathbf{3}$ & 512 & 537 & 75,000 & $0.17(0.71)$ & 8.3 & 30 & 40 \\
$\mathbf{4}$ & 514 & 528 & 100,000 & $0.11(0.73)$ & 14 & 9.1 & 31 \\
$\mathbf{5}$ & 562 & 603 & 45,500 & $0.02(0.39)$ & 12 & 8.7 & 35 \\
$\mathbf{6}$ & 614 & 646 & 114,000 & 0.02 & 71 & 2.8 & 37 \\
$\mathbf{R}^{d}$ & 530 & 556 & 105,000 & 0.95 & 5 & $190^{f}$ & $e$ \\
\hline
\end{tabular}

${ }^{a}$ Values on the left are for dyes in toluene; the following reference dyes and excitation wavelengths were used: 1-2, fluorescein in water, $460 \mathrm{~nm}$; 3-4, R6G in ethanol, $488 \mathrm{~nm}$; 5, Texas Red in ethanol, $532 \mathrm{~nm}$; 6, Cy5 in water, $594 \mathrm{~nm}$; values in parentheses are for dyes in a solid PMMA matrix referenced against KF241, a perylene derivative, in PMMA $\left(\Phi_{\mathrm{F}}=0.95\right)$ and pumped at $460 \mathrm{~nm}$ for $\mathbf{1 - 2}$ and $488 \mathrm{~nm}$ for $\mathbf{3}-\mathbf{5} .{ }^{b} \mathbf{1}-\mathbf{4}$ were measured at $488 \mathrm{~nm}, \mathbf{5}-\mathbf{6}$ at $594 \mathrm{~nm} .{ }^{c} \mathbf{1}-\mathbf{5}$ were measured at $488 \mathrm{~nm}, \mathbf{6}$ at $594 \mathrm{~nm}$. ${ }^{d} \mathbf{R}=\mathrm{R} 6 \mathrm{G}$ in ethanol ${ }^{7} .{ }^{e}$ Cation. ${ }^{f}$ Total photons emitted.

from 0.19 to 0.39 as the optical density of the film was lowered from 0.025 to 0.012 ; hence, the largest $\Phi_{\mathrm{F}}$ values observed are reported. The significant improvement of $\Phi_{\mathrm{F}}$ in the solid over solution indicates a correlation between the rigidity of the local environment and the strength of the fluorescence of these dyes, possibly due to the suppression of a twisted internal charge-transfer excited state. ${ }^{18}$ Therefore, these dyes should be useful as a singlemolecule probe of local environmental viscosity, rigidity, or polymer-free volume. ${ }^{19}$

The photobleaching quantum efficiency $\left(\Phi_{\mathrm{B}}\right)$ was determined for a bulk sample using an epifluorescence microscope, as described elsewhere, ${ }^{20}$ using a back-illuminated frame transfer CCD camera (Roper Scientific MicroMax) to collect the fluorescence. Samples were spun from a solution of $\sim 10^{-6} \mathrm{M}$ dye in PMMA/toluene ( $1 \%$ $\mathrm{m} / \mathrm{m}$ ) onto a glass cover slip. Molecules $\mathbf{1 - 4}$ were excited with the 488-nm emission of an Ar+ laser (Coherent INNOVA 200), 

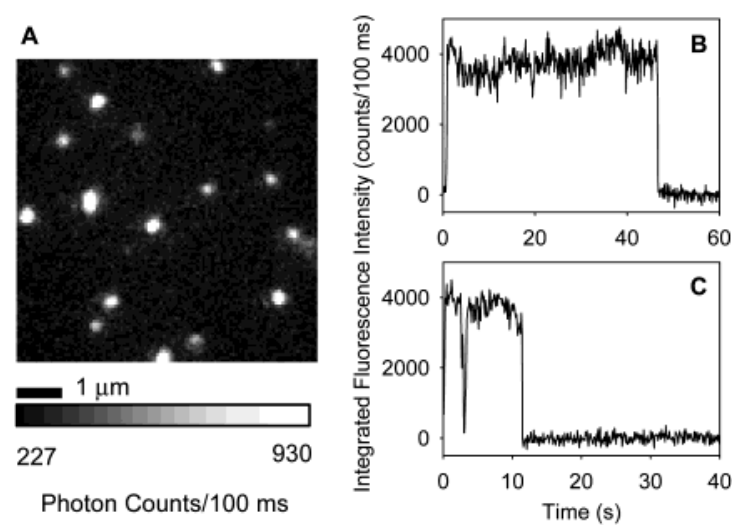

Figure 2. (A) Single molecules of $\mathbf{1}$ imaged in a PMMA film. The integrated fluorescence intensity of two individual molecules is shown in (B) and (C) as a function of time.

while 5-6 were pumped with 594-nm emission from a HeNe laser (Coherent). The $\Phi_{\mathrm{B}}$ values are quite small, easily comparable to one of the best single-molecule fluorophores (see $\mathbf{R}$ in Table 1).

Single molecules were observed using an epifluorescence microscope as described elsewhere..$^{20,21}$ Samples were prepared using spin-coated solutions of $\sim 10^{-10} \mathrm{M}$ dye in PMMA/toluene to ensure the molecules were separated more than the diffractionlimited spot diameter $(\sim 300 \mathrm{~nm})$. Figure 2 A shows a representative wide-field fluorescence image of individual molecules of $\mathbf{1}$ in PMMA that illustrates the high signal-to-background ratio $(\sim 7)$. The integrated fluorescence intensity as a function of time is shown in Figure 2, B and C, for two individual molecules. The digital photobleaching is characteristic of a single molecule. The molecule in Figure 2C exhibits blinking behavior similar to that observed in previous single-molecule experiments. ${ }^{22-24}$ Blinking was not observed for $\sim 85 \%$ of the molecules, demonstrating surprisingly good stability.

The total number of detected photons per molecule $\left(N_{\text {tot }}\right)$ was determined by integrating individual single-molecule time traces such as in Figure 2, B and C, to construct histograms. ${ }^{20,25}$ The values in the table are the means of these (exponential) distributions from 100 to 300 single molecules each. These values reflect only the number of photons that are detected and do not include losses due to filters and microscope optics. Including these losses brings the total number of emitted photons into better agreement with the inverse of $\Phi_{\mathrm{B}}$ as expected. For example, for $\mathbf{1}$, about $50 \%$ of the emission is collected through the microscope objective, ${ }^{26}$ and $41 \%$ is collected through the filters, yielding a total number of emitted photons of $1.2 \times 10^{6}$, a value that compares quite favorably to other single molecules. ${ }^{7,15}$

Because these dyes have favorable photophysical characteristics as well as novel properties not available with other single-molecule fluorophores, we foresee them being useful for an expanded array of single-molecule reporter experiments. For example, the dyes have significant electric dipole moments (Table 1), and the molecules are uncharged, requiring no counterion. Further, these dyes have a moderate hyperpolarizibility $\left(\beta_{0}\right)$ and large polarizability anisotropy $\left(\delta \alpha_{0}\right)$ that may lead to interesting nonlinear optical phenomena; for example, 5 has $\beta_{0}=241 \times 10^{-50} \mathrm{CV}^{-2} \mathrm{~m}^{3}$ and $\mathbf{6}$ has $\delta \alpha_{0}=$ $84 \times 10^{-40} \mathrm{CV}^{-1} \mathrm{~m}^{2} .{ }^{27}$ Additionally, the dependence of $\Phi_{\mathrm{F}}$ on viscosity or local rigidity may make these dyes useful as alternate probes of local environments. ${ }^{28}$ Last, these dyes offer considerable structural flexibility that permits a range of desired properties to be obtained. The group of dyes discussed here is a fraction of those available, and by synthetically modifying various functional groups off the main backbone, various properties of these molecules may be manipulated and optimized for specific applications, such as solubility in water. This opens a door to a variety of single-molecule experiments using this new class of dyes.

Acknowledgment. We acknowledge partial support from U.S. AFOSR Grant No. F49620-00-1-0038, and we thank R. Wortmann for providing nonlinear optical measurements.

\section{References}

(1) Moerner, W. E.; Orrit, M. Science 1999, 283, 1670-1676.

(2) Weiss, S. Science 1999, 283, 1676-1683.

(3) Deschenes, L. A.; Vanden Bout, D. A. Science 2001, 292, 255-258.

(4) Rigler, R.; Orrit, M.; Basche, T., Eds. Single Molecule Spectroscopy: Nobel Conference Lectures; Springer-Verlag: Berlin, 2001; Vol. 67.

(5) Higgins, D. A.; Hou, Y. In Encyclopedia of Nanoscience and Nanotechnology; Schwartz, J. A., Contescu, C., Putyera, K., Eds.; Marcel Dekker: New York, 2003. In press

(6) Tsien, R. Y.; Waggoner, A. In Handbook of Biological Confocal Microscopy, 2nd ed.; Pawley, J. B., Ed.; Plenum Press: New York, 1995 pp 267-279.

(7) Soper, S. A.; Nutter, H. L.; Keller, R. A.; David, L. M.; Shera, E. B. Photochem. Photobiol. 1993, 57, 972-977.

(8) Kulzer, F.; Koberling, F.; Christ, T.; Mews, A.; Basche, T. Chem. Phys. 1999, 247, 23-34.

(9) Nagao, Y.; Iwawaki, H.; Kozawa, K. Heterocycles 2002, 56, 331-340.

(10) Langhals, H.; Jaschke, H.; Ring, U.; von Unold, P. Angew. Chem., Int Ed. 1999, 38, 201-203.

(11) Blum, C.; Stracke, F.; Becker, S.; Mullen, K.; Meixner, A. J. J. Phys. Chem. A 2001, 105, 6983-6990.

(12) Bowden, N. B.; Willets, K. A.; Moerner, W. E.; Waymouth, R. M. Macromolecules 2002, 35, 8122-8125.

(13) Wright, D.; Gubler, U.; Roh, Y.; Moerner, W. E.; He, M.; Twieg, R. J. Appl. Phys. Lett. 2001, 79, 4274-4276.

(14) Ostroverkhova, O.; Wright, D.; Gubler, U.; Moerner, W. E.; He, M.; SastreSantos, A.; Twieg, R. J. Adv. Funct. Mater. 2002, 12, 621-629.

(15) Schmidt, T. Single Mol. 2001, 2, 217.

(16) Magde, D.; Wong, R.; Seybold, P. G. Photochem. Photobiol. 2002, 75, $327-334$.

(17) Melhuish, W. H. J. Opt. Soc. Am. 1964, 54, 183-186.

(18) Valeur, B. Molecular Fluorescence; Wiley-VCH: Weinheim, 2002

(19) Loutfy, R. O. Pure Appl. Chem. 1986, 58, 1239-1248.

(20) Peterman, E. J. G.; Brasselet, S.; Moerner, W. E. Biophys. J. 2002, 83, 2681.

(21) Vrjlic, M.; Nishimura, S.; Brasselet, S.; Moerner, W. E.; McConnell, H. M. Biophys. J. 2002. In press.

(22) Xie, X. S.; Dunn, R. C. Science 1994, 265, 361-364.

(23) Dickson, R. M.; Cubitt, A. B.; Tsien, R. Y.; Moerner, W. E. Nature 1997 $388,355-358$

(24) Moerner, W. E. Science 1997, 277, 1059.

(25) Lounis, B. L.; Deich, J.; Rosell, F. I.; Boxer, S. G.; Moerner, W. E. J. Phys. Chem. B 2001, 105, 5048-5054.

(26) Enderlein, J. Opt. Lett. 2000, 25, 634-636.

(27) He, M.; Sastre-Santos, A.; Twieg, R.; He, P.; Huang, S.; Ostroverkhova, O.; Gubler, U.; Wright, D.; Moerner, W. E.; Redi-Shiro, M.; Wortmann, R. 2002. Manuscript submitted.

(28) Hou, Y.; Bardo, A. M.; Martinez, C.; Higgins, D. A. J. Phys. Chem. B 2000, 104, 212-219.

JA029100Q 